\title{
The role of oestrogen receptor $\alpha$ in human thyroid cancer: contributions from coregulatory proteins and the tyrosine kinase receptor HER2
}

\author{
Dara O Kavanagh ${ }^{1}$, Marie Mcllroy, ${ }^{1,2}$, Eddie Myers ${ }^{1}$, Fiona Bane ${ }^{2}$, \\ Thomas B Crotty ${ }^{1}$, E McDermott $^{1}$, Arnold D Hill ${ }^{1,2}$ and Leonie S Young ${ }^{1,2}$ \\ ${ }^{1}$ School of Medicine and Medical Science, UCD Conway Institute, St Vincent's University Hospital and University College Dublin, \\ Dublin 4, Ireland \\ ${ }^{2}$ Endocrine Oncology Research Group, Department of Surgery, Royal College of Surgeons in Ireland, St Stephens Green, Dublin 2, \\ Ireland \\ (Correspondence should be addressed to L S Young at Endocrine Oncology Research Group, Department of Surgery, Royal College \\ of Surgeons in Ireland; Email: lyoung @ rcsi.ie)
}

\begin{abstract}
Epidemiological, clinical, and molecular studies suggest a role for oestrogen in thyroid cancer. How oestrogen mediates its effects and the consequence of it on clinical outcome has not been fully elucidated. The participation of coregulatory proteins in modulating oestrogen receptor (ER) function and input of crosstalk with the tyrosine kinase receptor HER2 was investigated. Oestrogen induced cell proliferation in the follicular thyroid cancer (FTC)-133 cells, but not in the anaplastic $8305 \mathrm{C}$ cell line. Knockdown of the coactivator steroid receptor coactivator (SRC)-1 inhibited FTC-133 basal, but not oestrogen induced, cell proliferation. Oestrogen also increased protein expression of SRC-1 and the ER target gene cyclin D1 in the FTC-133 cell line. ER $\alpha$, ER $\beta$, the coregulatory proteins SRC-1 and nuclear corepressor (NCoR), and the tyrosine kinase receptor HER2 were localised by immunohistochemistry and immnofluorescence in paraffinembedded tissue from thyroid tumour patients $(n=111)$. ER $\alpha$ was colocalised with both SRC-1 and NCoR to the nuclei of the tumour epithelial cells. Expression of ER $\alpha$ and NCoR was found predominantly in non-anaplastic tumours and was significantly associated with well-differentiated tumours and reduced incidence of disease recurrence. In non-anaplastic tumours, HER2 was significantly associated with SRC-1, and these proteins were associated with poorly differentiated tumours, capsular invasion and disease recurrence. Totally, $87 \%$ of anaplastic tumours were positive for SRC-1. Kaplan-Meier estimates of disease-free survival indicated that in thyroid cancer, SRC-1 strongly correlates with reduced disease-free survival $(P<0.001)$, whereas NCoR predicted increased survival $(P<0.001)$. These data suggest opposing roles for the coregulators SRC-1 and NCoR in thyroid tumour progression.
\end{abstract}

Endocrine-Related Cancer (2010) 17 255-264

\section{Introduction}

Thyroid carcinoma constitutes $1 \%$ of all new malignant disease. Of these, $94 \%$ are differentiated follicular or papillary carcinomas. A further $5 \%$ are medullary carcinomas derived from neuroendocrine cells. The remaining are anaplastic tumours arising from dedifferentiation of the differentiated type (Figge 1999). In view of the low incidence and largely favourable prognosis, therapeutic advances are minimal. Despite multimodal therapy, there has been no improvement in survival rates over the past two decades (Teppo et al. 1998, Sherman 2003).

Malignant disease of the thyroid gland is three times more common in females than in males. Despite this, the prognosis is more favourable in females. Welldifferentiated carcinomas have a female preponderance 
and are most frequent in the postpubertal and premenopausal age groups. The use of the oral contraceptive pill is associated with a higher risk of thyroid cancer. An increased incidence is similarly seen in patients treated with oestrogen therapy for gynaecological conditions, but not for postmenopausal patients treated with low-dose oestrogen replacement therapy. Recently, it has been shown that among parous women of reproductive age, a recent pregnancy is associated with approximately a doubling in thyroid cancer risk. Pregnancy is associated with elevated serum thyroid hormone and oestrogen level, further supporting a role for oestrogen in thyroid carcinogenesis (Rossing et al. 2000). This gender difference is observed worldwide and suggests that thyroid tumour development and progression may be influenced by oestrogen as previously demonstrated in breast cancer. Furthermore, Kishino et al. (1997) identified a beneficial role for high-dose tamoxifen in multidrug resistant thyroid cancer.

Oestrogens play a critical role in endocrine tumours, including those of the breast, prostate and thyroid. Oestrogen mediates its genomic actions through binding its nuclear receptor leading to transcription and translation of genes relevant to tumour progression. The oestrogen receptor (ER) is encoded for by two genes, ER $\alpha$ and ER $\beta$. Though both isoforms of the receptor have been identified in human thyroid tumour tissue, it is $E R \alpha$ that has been associated with increased oestrogen-dependent cell proliferation (Zeng et al. 2008). Oestrogen can also mediate its effects independently of its classic nuclear receptor. Studies in the thyroid have shown that oestrogen can utilise the G-coupled protein GPCR30 to drive both gene transcription and cellular growth (Vivacqua et al. 2006).

Central to the functioning of ER are the coregulatory proteins. These are present at rate-limiting amounts in the nucleus, thereby regulating transcription of target genes. Coactivators possess histone acetylation activity, which may directly influence gene expression through local depression of chromatin. These coactivators include the p160 $(160 \mathrm{kDa})$ protein family members steroid receptor coactivator (SRC-1) and amplified in breast cancer (AIB-1). In the absence of ligand, the ER maintains transcriptional silencing through recruitment of the nuclear corepressors (NCoRs) silencing mediator of retinoid and thyroid receptors and NCoR (Chen \& Evans 1995, Jenster \& Spencer 1997). On binding to its receptor, oestrogen releases the resident corepressor and recruits coactivator in order to initiate successful transcription and translation of the target gene (Smith \& O'Malley 2004). In the setting of breast cancer, these molecular switches have been shown to be prognostically significant (Myers et al. 2004, McIlroy et al. 2006). Aberrant expression of $\mathrm{p} 160$ proteins has been associated with resistance to endocrine therapies and the development of tumour recurrence (Osborne et al. 2003, Redmond et al. 2009). Furthermore, unlike other oncogenes, recent studies provide evidence of a specific role for SRC-1 in the development of metastasis (Qin et al. 2009, Wang et al. 2009). The presence of the coregulatory proteins in thyroid cancer and their prognostic significance, if any, have not yet been examined.

We hypothesised that ER signalling plays a role in the progression of thyroid cancer. To test this, we examined the proliferative effects of oestrogen in thyroid cancer and the effects of oestrogen on the expression of its target gene, cyclin D1. In addition, we analysed a cohort of thyroid cancer patients to determine the presence and significance of $E R \alpha, E R \beta$ and the coregulatory proteins, SRC- 1 and NCoR, and the tyrosine kinase receptor HER2 in relation tumour type and disease progression.

\section{Materials and methods}

\section{Patient selection}

Tumour specimens from consecutive patients with thyroid cancer treated at St Vincent's University Hospital, Dublin from 1990 to 2001 were selected. Histologically, normal thyroid tissue specimens were obtained from patients who underwent surgery for multinodular goitre. The cancer specimens arose from patients who had not had previous therapy for thyroid cancer and had undergone primary surgical resection. Patients with non-anaplastic tumours $<10 \mathrm{~mm}$ underwent surgery alone, and those with tumours $>10 \mathrm{~mm}$ underwent surgery followed by radio-iodine therapy. Patients with anaplastic tumours received radio-therapy.

\section{Clinicopathological parameters}

Variables analysed included size, pathological subtype, extremes of age $(<10$ and $>40)$, gender, degree of differentiation and capsular invasion. Median follow-up was 10.2 years.

\section{Immunohistochemistry}

Five micron ( $5 \mu \mathrm{m}$ thick) tissue sections were taken from paraffin-embedded thyroid cancer and multinodular goitre. Following antigen retrieval, sections were incubated with primary antibodies as 
follows: rabbit anti-human $\mathrm{ER} \alpha(1 \mu \mathrm{g} / \mathrm{ml})$, rabbit anti-human SRC-1 $(1 \mu \mathrm{g} / \mathrm{ml})$, rabbit anti-human NCoR $(1 \mu \mathrm{g} / \mathrm{ml}$; Santa Cruz Biotechnology, Santa Cruz, CA, USA) and mouse anti-human ER $\beta(5 \mu \mathrm{g} / \mathrm{ml}$; Serotec, Oxford, UK). The primary antibodies were incubated for $1 \mathrm{~h}$ at room temperature. Sections were subsequently incubated with the corresponding biotinlabelled secondary antibody $(0.5 \%$ in PBS; Vector Laboratories, Burlingame, CA, USA) for $30 \mathrm{~min}$, followed by peroxidase-labelled avidin-biotin complex (Vector Laboratories) for $30 \mathrm{~min}$. Sections were developed in 3,3-diaminobenzidine tetrahydrochloride for $8 \mathrm{~min}$ and counterstained with haematoxylin for $3 \mathrm{~min}$, then passed through increasing concentrations of industrial methylated spirits (IMS) (70 and 100\%) and then xylene. Immunostained slides were scored using the Allred scoring system (Harvey et al. 1999). A combined score of three or higher was defined as positive staining. Each slide was observed by two independent observers blinded to the clinicopathological factors of interest. The interobserver correlation coefficient was determined. These coefficients ranged from 0.909 to 0.972 indicating a high level of interobserver reliability (Fleiss 1986).

\section{Assessment of HER2 status}

HER2 status was evaluated using the Dako (Glostrup, Denmark) HercepTest immunocytochemical assay. Scoring was assessed according to the manufacturer's instructions (0-3). In tumour samples scoring +2 with the Hercept test, HER2 status was confirmed by fluorescent in situ hybridisation using the PathVysion kit probe to detect amplification of the HER2 gene (spectrum orange labelled HER2 and spectrum green labelled $\alpha$ satellite centromeric region for chromosome 17; Vysis Inc., Downers Grove, IL, USA) according to the manufacturer's instructions.

\section{Immunofluoresence}

Thyroid cancer sections were prepared as above and incubated in goat serum $(\mathrm{ER} \alpha)$ for $60 \mathrm{~min}$. Goat antirabbit $\mathrm{ER} \alpha(10 \mu \mathrm{g} / \mathrm{ml}$ in $10 \%$ human serum $)$ was placed on each slide for $90 \mathrm{~min}$. The sections were rinsed in PBS and incubated with the corresponding secondary fluorochrome-conjugated antibody (1 in 100; SigmaAldrich) for $60 \mathrm{~min}$. The slides were rinsed in PBS and blocked in rabbit serum for 90 min and washed with PBS. Each slide was incubated with either rabbit antihuman SRC-1 or rabbit anti-human NCoR (both $10 \mu \mathrm{g} / \mathrm{ml}$ in $10 \%$ human serum) for $90 \mathrm{~min}$, followed by a wash in PBS. The slides were incubated with the corresponding fluorochrome-conjugated antibody
(1 in 100) for $60 \mathrm{~min}$. Sections were rinsed in PBS and mounted (Dako). Sections were examined under a fluorescent microscope. Negative controls were performed using matched $\mathrm{IgG}$, and no staining was detected.

\section{Cell culture treatments}

The follicular thyroid cancer (FTC)-133 cell line (ECACC, Wiltshire, UK) was grown in DMEM and Ham's F12 (1:1) supplemented with 10\% FCS and $2 \mathrm{mM}$ L-glutamine (Gibco). The 8305C anaplastic thyroid cancer cell line 8305C (ECACC) was grown in EMEM (Sigma) supplemented with $10 \%$ FCS, $2 \mathrm{mM}$ L-glutamine and $1 \%$ non-essential amino acids. Cells were incubated in a humidified atmosphere of $5 \% \mathrm{CO}_{2}$ at $37^{\circ} \mathrm{C}$. Experiments were carried out when cells reached $90 \%$ confluence. Cells were maintained in steroid and phenol-free minimum essential medium (Gibco) for $72 \mathrm{~h}$ prior to treatment. Cells were then incubated in the presence and absence of $17 \beta$-oestradiol $\left(\mathrm{OE}_{2}\right)$ or Faslodex (ICI 182 780) $(10 \mathrm{nM})$ for $24 \mathrm{~h}$ and then harvested.

\section{Western blotting}

Proteins $(100 \mu \mathrm{g})$ were resolved on a polyacrylamide gel (12\% for ER $\alpha, \mathrm{SRC}-1$ and cyclin D1, and $6 \%$ for $\mathrm{NCoR}$ ) at $110 \mathrm{~V}$ for $120 \mathrm{~min}$ and were transferred to a nitrocellulose membrane ( $250 \mathrm{~mA}$ for $60 \mathrm{~min}$ for $\mathrm{ER} \alpha$, SRC-1 and cyclin D1, and $90 \mathrm{~min}$ for NCoR). Membranes were incubated for $60 \mathrm{~min}$ in blocking buffer (5\% non-fat dry milk and $0.05 \%$ Tween- 20 in TBS) at room temperature and subsequently with primary antibody, rabbit anti-human ER $\alpha(2 \mu \mathrm{g} / \mathrm{ml})$, rabbit anti-human ER $\beta(2 \mu \mathrm{g} / \mathrm{ml})$, rabbit anti-human SRC-1 $(2 \mu \mathrm{g} / \mathrm{ml})$, rabbit anti-human NCoR $(2 \mu \mathrm{g} / \mathrm{ml})$ or rabbit anti-human cyclin D1 $(2 \mu \mathrm{g} / \mathrm{ml})$ in blocking buffer overnight at $4{ }^{\circ} \mathrm{C}$. The membranes were washed prior to incubation with the corresponding HRP secondary antibody ( 1 in 2000 for ER $\alpha$, ER $\beta$, cyclin D1 and SRC-1, and 1 in 3300 for NCoR) in blocking buffer for $60 \mathrm{~min}$ at room temperature. The membranes were washed and developed with intensified chemiluminescence (Pierce, Rockford, IL, USA).

\section{Proliferation assays}

The FTC-133 and 8305C cells were seeded on a 12 -well plate. Cells were treated with either $10 \mathrm{nM}$ $17-\mathrm{OE}_{2}$ or ICI-182 780 alone or in combination as described above. Methyl thioazole tetrazolium $(500 \mu \mathrm{g} / \mathrm{ml})$ was added to each well, and following a 4-h incubation period, absorbance was read at $570 \mathrm{~nm}$. 


\section{SiRNA}

Pre-designed and validated siRNA directed against SRC-1 (Ambion, Austin, TX, USA, cat no. 115458) were used in the knockdown studies (Redmond et al. 2009).

\section{Flow cytometry}

Cells were harvested by centrifugation at $200 \mathrm{~g}$ for $4 \mathrm{~min}$ and washed in $10 \mathrm{ml}$ ice-cold PBS. Cell pellets were resuspended in $200 \mu \mathrm{l}$ PBS and fixed in $2 \mathrm{ml}$ ice-cold $70 \%(\mathrm{v} / \mathrm{v})$ ethanol at $4{ }^{\circ} \mathrm{C}$ overnight. Cells were centrifuged at $300 \mathrm{~g}$ for $4 \mathrm{~min}$, ethanol was removed and the pellets were resuspended in $400 \mu \mathrm{l}$ PBS. RNase A $(0.5 \mathrm{mg} / \mathrm{ml})$ and propidium iodide $(200 \mu \mathrm{M})$ were added, and samples were incubated in the dark at $37^{\circ} \mathrm{C}$ for $30 \mathrm{~min}$. Cell cycle profiles were analysed on an Accuri C6 flow cytometer using CFlow Software.

\section{Statistical analysis}

Univariate analysis was performed using Fisher's exact test for categorical variables and using Wilcoxon's test for continuous variables. Two-sided $P$ values of $<0.05$ were considered to be statistically significant. Kaplan-Meier estimates of disease-specific survival functions were computed, and the Wilcoxon test was used to compare survival curves.

\section{Results}

\section{Thyroid cancer cell cycle, proliferation and protein expression}

Cell cycle phase of follicular (FTC-133) and anaplastic (8305C) thyroid cancer cell lines was assessed by flow cytometry. Anaplastic thyroid cancer cells had a greater percentage of cells in the $G_{2} / M$ phase in comparison to the follicular cell line (Fig. 1A). There was no discernable difference observed in cell cycle phase in either of the thyroid cancer cells following treatment with $\beta-\mathrm{OE}_{2}$. However, oestrogen increased overall cellular proliferation of the FTC-133 cell line (Fig. 1B). The ER antagonist ICI 182780 (Faslodex) inhibited oestrogen-dependent FTC-133 cell proliferation. Oestrogen had no effect on cell proliferation in the $8305 \mathrm{C}$ cell line.

Treatment with oestrogen increased protein expression of the ER coactivator SRC-1 and its target gene cyclin D1 in the FTC-133 cell line (Fig. 1C) and decreased expression of ER $\beta$, with no alterations in $\mathrm{ER} \alpha, \mathrm{NCoR}$ or HER2 protein expression detected (Fig. 1C). In contrast, in the $8350 \mathrm{C}$ cells, oestrogen failed to significantly alter protein expression of ER, its target gene cyclin D1 or HER2 (Fig. 1C). Levels of SRC-1 and NCoR were found to be low in the 8305C cell line. Knockdown of SRC-1 significantly retarded basal cell proliferation in the FTC-133 cells, but had no effect on oestrogen-induced cell proliferation or on proliferation in the $8305 \mathrm{C}$ cell line (Fig. 1D).

\section{Localisation of ER and coregulatory proteins in human thyroid cancer tissue}

$\mathrm{ER} \alpha, \mathrm{ER} \beta, \mathrm{SRC}-1$ and NCoR were all found to be expressed in a subset of thyroid tumour patients. ER $\alpha$ and the coregulatory proteins were strongly expressed in the nucleus with some cytoplasmic staining also observed (Fig. 2A). Expression of SRC-1 was detected exclusively in the tumour tissue, whereas $\mathrm{ER} \alpha$ and $\mathrm{NCoR}$ were also present in the surrounding normal and goitre tissue. In patients who were positive for ER $\alpha$ and the coregulatory proteins, ER $\alpha$ was found to colocalise with both SRC-1 and NCoR in the nucleus of the tumour epithelial cells (Fig. 2B).

\section{Expression of ER and coregulatory proteins in thyroid tumour subtypes}

Qualitative expression of the receptors ER $\alpha$ and HER2, along with the coregulatory proteins SRC-1 and NCoR, was examined in subtypes of thyroid cancers (Fig. 3A). $\mathrm{ER} \alpha$ and NCoR were found to be expressed in both normal thyroid tissue and non-anaplastic tumours, including papillary, follicular and adenoma. ER $\beta$ was found to be expressed predominantly in papillary tumours. A low percentage $(<10 \%)$ of papillary and follicular tumours expressed SRC-1. In contrast, a high percentage of anaplastic tumours (87\%) expressed SRC-1, and a low number of these tumours were positive for $\mathrm{ER} \alpha$.

In the patient population, ER $\alpha$ expression was positively associated with $\mathrm{NCoR}$ and negatively associated with HER2 and SRC-1 (Table 1). In terms of clinicopathological characteristics, no association was observed between expression of the ER $\alpha$ and the coregulatory proteins in relation to extremes of age ( $<10$ and $>40$ years), gender or tumour size. ER $\alpha$ and $\mathrm{NCoR}$ expression was positively associated with well-differentiated tumours and inversely with disease recurrence. Whereas, both the tyrosine kinase receptor HER2 and coactivator SRC-1 associated with capsular invasion and recurrence (Table 1).

Kaplan-Meier estimates of disease-free survival indicate that patients with anaplastic tumours have significantly reduced survival compared with 

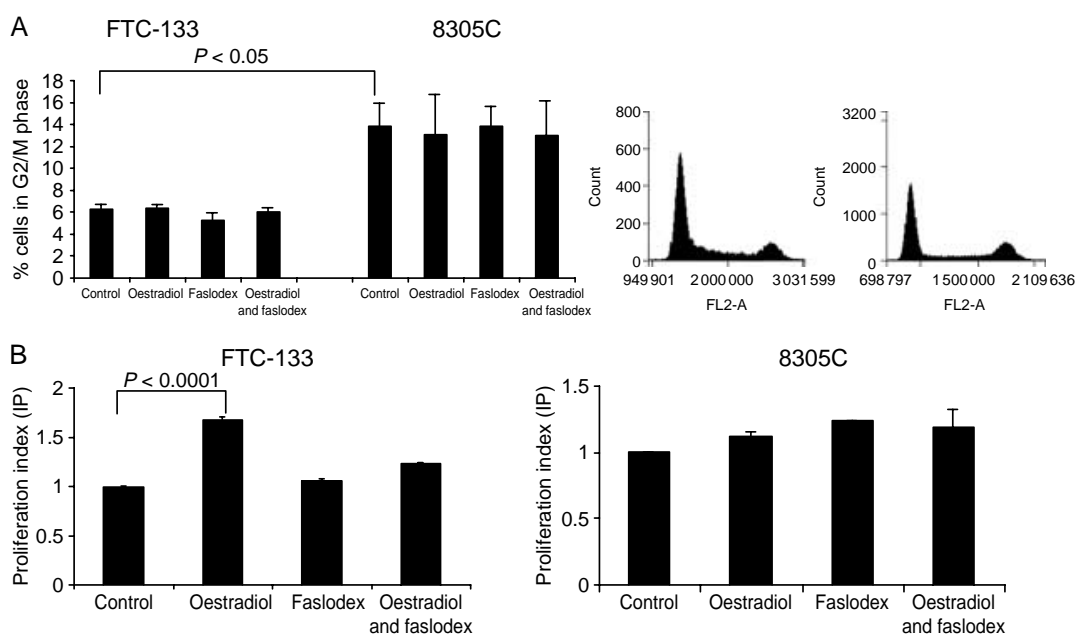

C
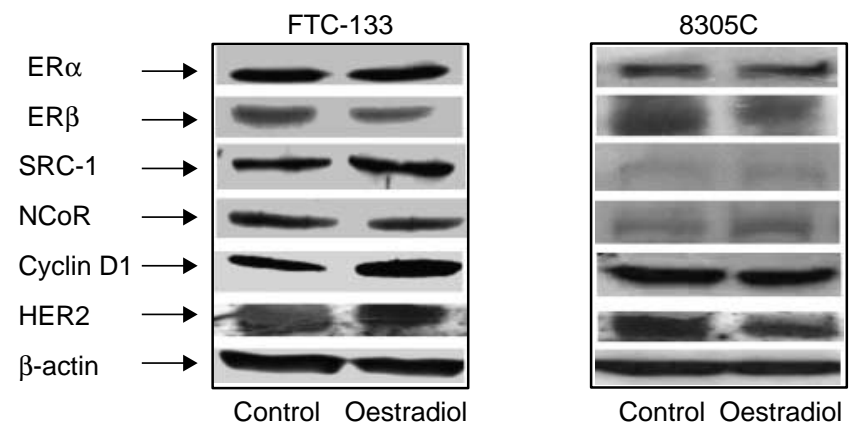

Control Oestradiol
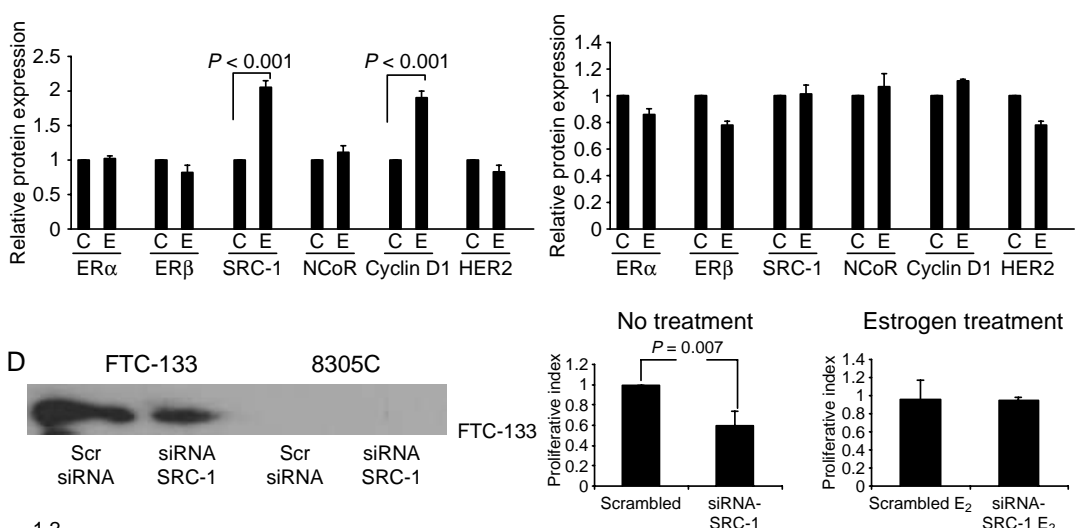

Estrogen treatment

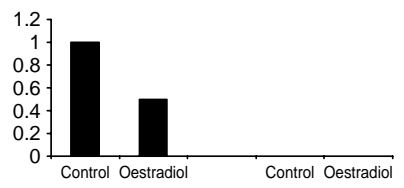

$8305 \mathrm{C}$
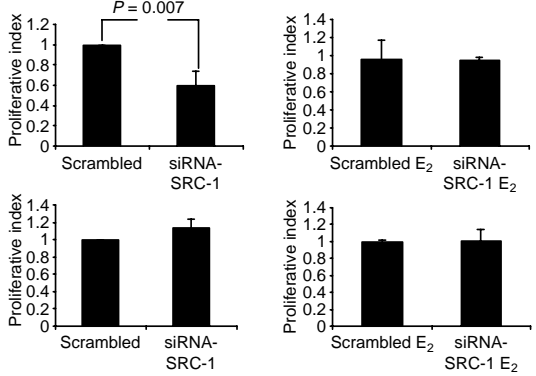

Figure 1 (A) Flow cytometry analysis of cell cycle phase in follicular (FTC-133) and anaplastic (8305C) breast cancer cell lines. Percentage of cells in follicular (FTC-133) and anaplastic (8305C) thyroid cancer cell lines. Percentage of cells in $\mathrm{G}_{2} / \mathrm{M}_{\text {phase }}$ under control conditions and following treatment with $17 \beta$-oestradiol and Faslodex (48 h) alone and in combination. Results are expressed as mean \pm s.D. of individual experiments $(n=3)$. (B) Cell proliferation was analysed by MTT assay. FTC-133 and $8305 \mathrm{C}$ thyroid cancer cells were cultured in the presence of $17 \beta$-oestradiol and Faslodex ( $24 \mathrm{~h}$ ) alone and in combination. Results are expressed as mean \pm s.D. of individual experiments $(n=3)$. (C) Protein expression of ER $\alpha$, ER $\beta$, SRC-1, NCoR and cyclin D1 in the FTC-133 and $8305 \mathrm{C}$ human thyroid cancer cell line was assessed by western blotting post-incubation with $\beta$-oestradiol (E) (24 h). Membranes were also probed for $\beta$-actin. Optical density readings were calculated relative to $\beta$-actin, control values $(C)$ were normalised to one and the treated group was expressed as a ratio. Results are expressed as mean \pm S.D. $(n=3)$. (D) Successful knockdown of SRC-1 with siRNA was confirmed by western blot. Knockdown of SRC-1 inhibited basal cell proliferation in the follicular (FTC-133), but not anaplastic (8305C) thyroid cancer cell line. Results are expressed as mean \pm s.D. $(n=3)$. 
A

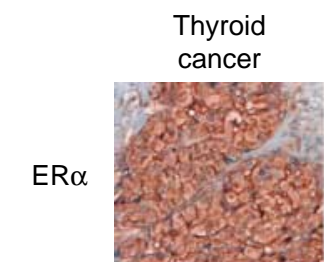

SRC-1

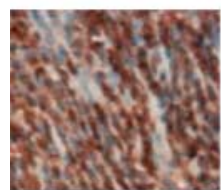

$\mathrm{NCoR}$

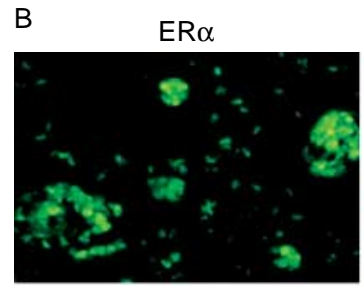

$\mathrm{ER} \alpha$

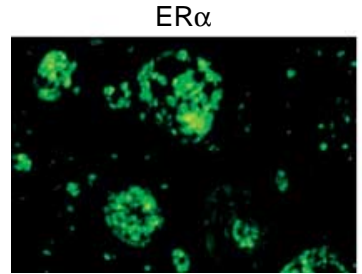

IgG-matched control
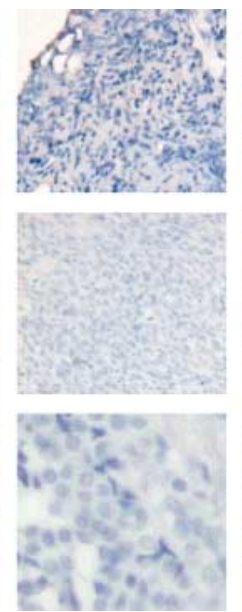

SRC-1

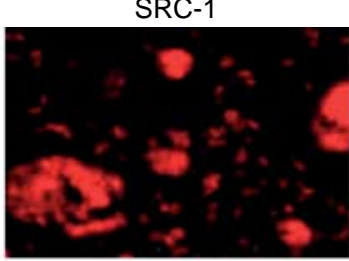

NCoR

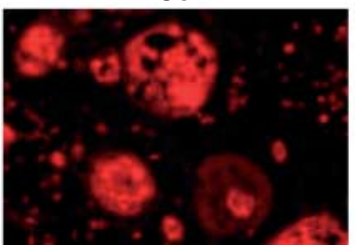

Normal thyroid
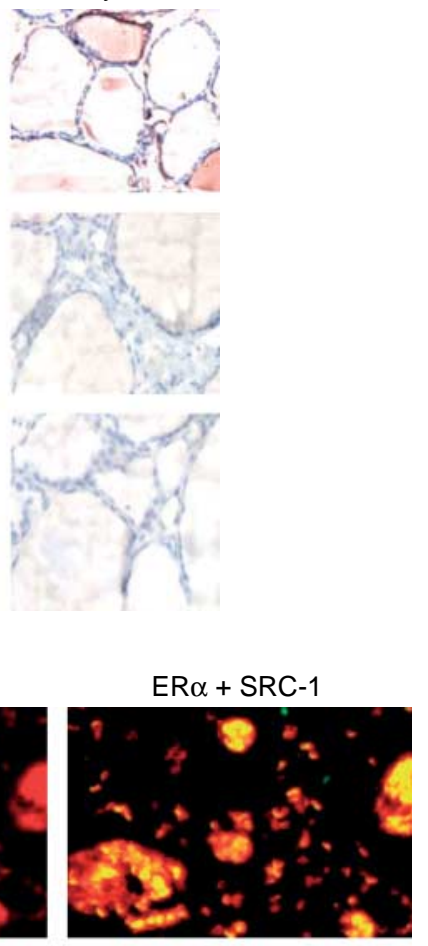

$\mathrm{ER} \alpha+\mathrm{NCoR}$

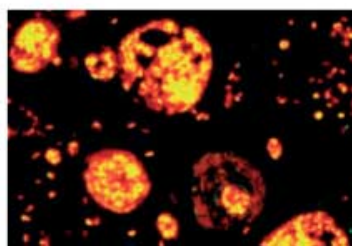

Figure 2 (A) Immunohistochemical localisation of $E R \alpha, S R C-1$ and NCoR counterstained with haematoxylin and matched IgG-negative controls in human thyroid cancer $(200 \times)$ and normal thyroid $(200 \times)$. (B) Immunofluorescent colocalisation of ER $\alpha$ with SRC-1 and NCoR in human thyroid cancer.

non-anaplastic tumours $(P<0.001$; Fig. 3B). In the whole patient cohort, SRC-1 significantly predicted poor disease-free survival $(P<0.001)$, whereas expression of $\mathrm{NCoR}$ predicted a good prognosis $(P<0.001$; Fig. 3B $)$.

In order to more clearly define a role for these coregulatory proteins in thyroid cancer subtypes, we analysed expression of SRC-1, NCoR and HER2 expression in anaplastic versus non-anaplastic tumours (Table 2). NCoR was expressed in 55\% of nonanaplastic tumours and associated positively with well-differentiated cancers $(P<0.001)$. Both SRC-1 and HER2 were expressed in $17 \%$ of non-anaplastic tumours, and these proteins were significantly associated with each other $(P<0.001)$ and with disease recurrence $(P=0.001$ and $P<0.005$ respectively). Totally, $87 \%$ of anaplastic tumours were positive for
SRC-1, whereas no expression of either NCoR or HER2 was observed. All patients with anaplastic tumours had a disease recurrence (Table 2).

\section{Discussion}

Epidemiological, translational and clinical evidence suggests a role for oestrogens in the development of thyroid cancer (Kishino et al. 1997, Rossing et al. 2000, Lee et al. 2003, Zeng et al. 2008). Recent reports suggest that oestrogen can increase ER $\alpha$ expression in non-anaplastic papillary cancer cells, increase cellular proliferation and inhibit pro-apoptotic protein expression. In thyroid cancer, oestrogen can also activate extranuclear effects of ER, in particular by signalling through the $G$ protein-coupled receptor GPR30 (Vivacqua et al. 2006). No alteration, however, 
A

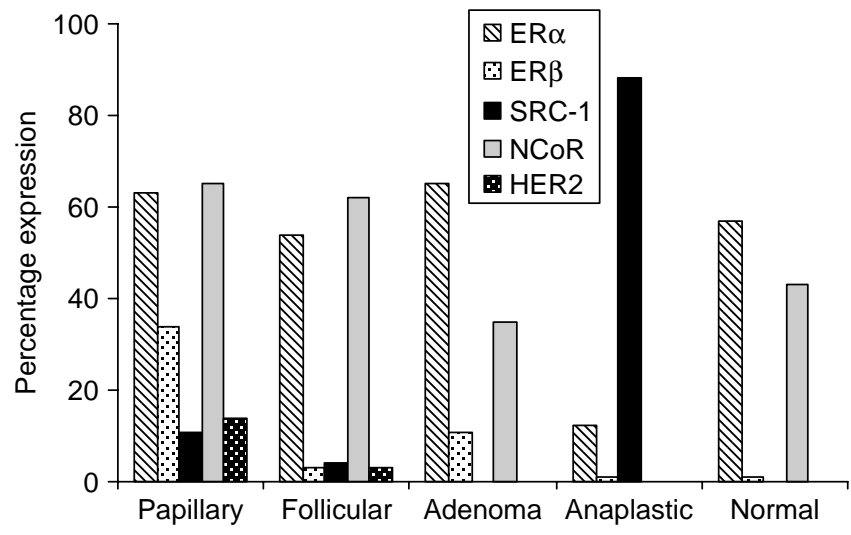

B

$$
\text { (i) Anaplastic }
$$

Kaplan-Meier survival estimates -
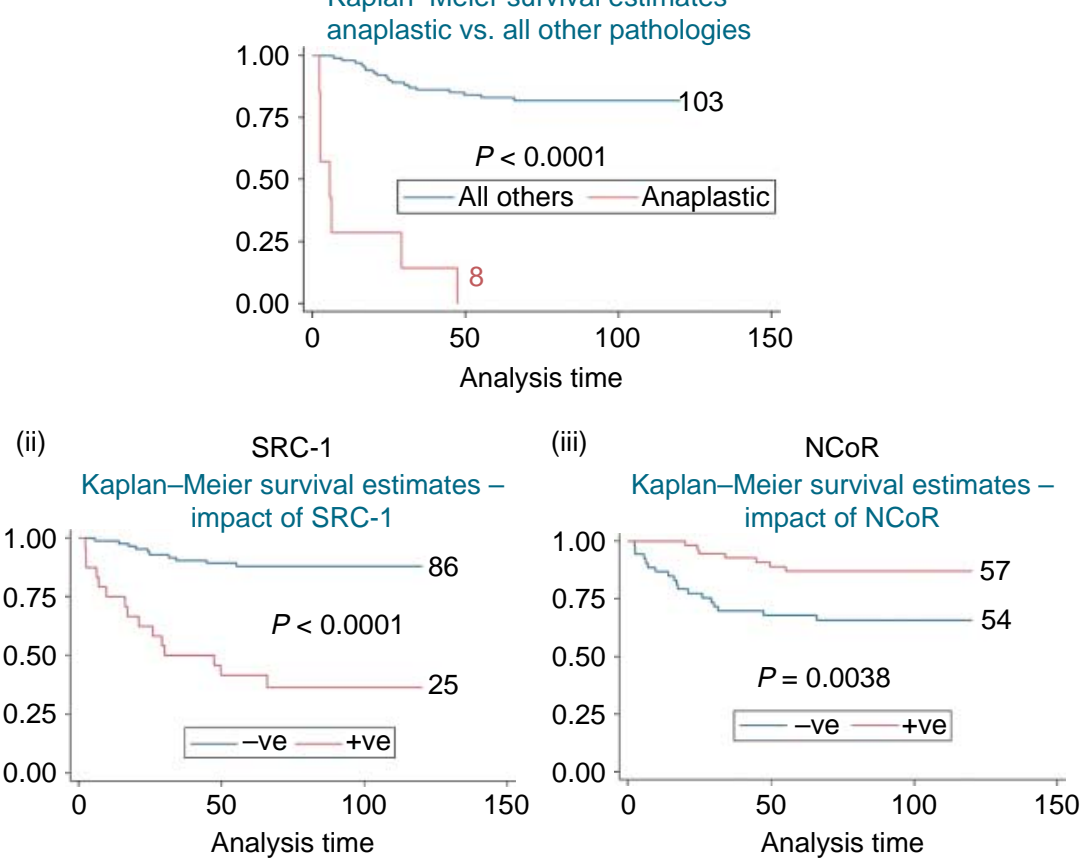

Figure 3 (A) Expression levels of ER $\alpha$, ER $\beta$, SRC-1, NCoR and HER2 in thyroid cancer specimens represented as percentages observed in each of the pathological subtypes encountered. (B) Patients with anaplastic disease were found to have a significantly reduced period of disease-free survival (i). Positivity for SRC-1 was shown to result in poor survival (ii), whereas expression of NCoR associates with longer disease remission (iii).

in cellular proliferation in anaplastic thyroid carcinoma cells has been observed. In this study, we employed cell line models of follicular and anaplastic thyroid cancer. The follicular cancer cells (FTC-133) were originally derived from a lymph node metastasis of a follicular thyroid carcinoma. These cells do, however, retain differentiated thyrocytic function and are responsive to growth factors. The anaplastic cell line, $8305 \mathrm{C}$, was established from an undifferentiated thyroid and is positive for both EGFR and HER2 (Murakawa et al. 2005). From cell cycle analysis, $8305 \mathrm{C}$ cells had a greater percentage of cells in the
$\mathrm{G}_{2} / \mathrm{M}$ phase in comparison to the FTC-133 cells. oestrogen had no effect on cell cycle phase in either cell line. However, in the FTC-133 cells, oestrogen induced cellular proliferation, which was inhibited by the ER antagonist ICI 182780 (Faslodex) and increased protein expression of its target gene cyclin D1. In our patient cohort, ER $\alpha$ was found to be highly expressed in both normal thyroid tissue and non-anaplastic tumours, including papillary, follicular and adenoma. However, only $10 \%$ of anaplastic tumours were positive for $\mathrm{ER} \alpha$. Expression of the steroid receptor was positively associated with well-differentiated tumours and 
Table 1 Associations with clinicopathological parameters as determined by Fisher's exact test. Association of variables oestrogen receptor $\alpha(E R \alpha)$, steroid receptor coactivator-1 (SRC-1), nuclear corepressor (NCoR), HER2 and recurrence were evaluated in conjunction with clinical classifications

\begin{tabular}{|c|c|c|c|c|c|c|}
\hline & Total & $\begin{array}{c}\text { ER } \alpha \text { positive } \\
\quad(n=63)\end{array}$ & $\begin{array}{c}\text { SRC-1 positive } \\
\quad(n=25)\end{array}$ & $\begin{array}{l}\text { NCoR positive } \\
\qquad(n=57)\end{array}$ & $\begin{array}{l}\text { HER2 positive } \\
\quad(n=18)\end{array}$ & $\begin{array}{l}\text { Recurrence } \\
\quad(n=27)\end{array}$ \\
\hline Capsular invasion ( $P$ value) & $n=24$ & $9 / 63(0.028)^{a}$ & $13 / 25(<0.001)$ & $5 / 57(=0.001)^{\mathrm{a}}$ & $17 / 18(<0.001)$ & $7 / 27$ (0.593) \\
\hline Well differentiated ( $P$ value $)$ & $n=76$ & $54 / 63(<0.001)$ & $1 / 25(<0.001)^{a}$ & $52 / 57(<0.001)$ & $0 / 18(<0.001)^{a}$ & $7 / 27(<0.001)^{a}$ \\
\hline $\mathrm{ER} \alpha$ positive & $n=63$ & - & $5 / 25(<0.001)^{a}$ & $42 / 57(<0.001)$ & $5 / 18(=0.009)$ & $10 / 27(0.025)^{a}$ \\
\hline SRC-1 positive ( $P$ value) & $n=25$ & $5 / 63(<0.001)^{\mathrm{a}}$ & - & $1 / 57(<0.001)^{a}$ & $11 / 18(<0.001)$ & $16 / 27(<0.001)$ \\
\hline NcoR positive ( $P$ value) & $n=57$ & $42 / 63(<0.001)$ & $1 / 25(<0.000)^{a}$ & - & $2 / 18(<0.001)^{a}$ & $8 / 27(=0.014)^{a}$ \\
\hline HER2 positive ( $P$ value) & $n=18$ & $5 / 63(0.007)^{a}$ & $11 / 25(<0.001)$ & $2 / 57(<0.001)^{a}$ & - & $8 / 27$ (0.039) \\
\hline Recurrence & $n=27$ & $4 / 63(0.003)^{a}$ & $12 / 25(<0.001)$ & $2 / 57(<0.001)^{a}$ & $7 / 18(0.007)$ & - \\
\hline
\end{tabular}

${ }^{\mathrm{a}}$ Reverse relationship.

inversely with disease recurrence. These data suggest that in thyroid cancer, oestrogen signalling is associated with non-aggressive, well-differentiated tumours, which have a favourable prognosis. Where the proliferation of thyroid cancer cells is promoted by $\mathrm{ER} \alpha$, proliferation is thought to be reduced by enhanced expression of ER $\beta$ (Zeng et al. 2008). In this study, ER $\beta$ expression was observed in both the follicular and anaplastic cancer cell lines; however, at a tissue level, $\mathrm{ER} \beta$ was found to be expressed predominantly in papillary thyroid cancer patients, suggesting that a functional role for ER $\beta$ may be principally in this cancer subtype.

The magnitude of ER gene regulation is influenced not only by the ligand, but also by the presence of specific co-regulatory proteins, present at rate-limiting levels, which modulate transcription. Studies from our group in breast cancer suggest that while expression of the coactivator protein SRC-1 correlates with reduced time to disease recurrence, the presence of the corepressor NCoR predicts enhanced disease-free survival (Myers et al. 2005, Al-azawi et al. 2008, Redmond et al. 2009). In the thyroid patient population, NCoR was found exclusively in the non-anaplastic tumours and normal thyroid tissue. The corepressor significantly associated with expression of ER $\alpha$, inversely associated with capsular invasion and positively with well-differentiated tumours. Furthermore, Kaplan-Meier estimates of disease-free survival demonstrated that NCoR significantly predicted enhanced survival in thyroid cancer patients. In contrast, in the FTC-133 follicular cancer cell line, SRC-1 protein expression was elevated in the presence of oestrogen, and knockdown of the coactivator protein inhibited cell proliferation. However, knockdown of SRC-1 had no effect on oestrogen-induced FTC-133 cell growth, suggesting that coactivator functional redundancy similar to that seen in the breast may also be relevant in thyroid cancer (Xu \& Li 2003). SRC-1 was expressed in a subset of non-anaplastic patients. Expression of SRC-1 was associated with disease recurrence and inversely associated with well-differentiated tumours. Though only low levels of SRC-1 were detected in the 8305C anaplastic cell line and knockdown of the coactivator had no effect on cell proliferation, SRC-1 was found to be highly expressed in the anaplastic patient population. These observations are in line with recent studies in the breast, which describe a specific role for SRC-1 in the development of tumour metastasis (Qin et al. 2009, Wang et al. 2009). Furthermore, in the entire thyroid cancer patient population, there was a

Table 2 Association of steroid receptor coactivator-1 (SRC-1), nuclear corepressor (NCoR), HER2, differentiation and recurrence were evaluated by Fisher's exact test in the anaplastic and non-anaplastic patient populations

\begin{tabular}{|c|c|c|c|c|c|c|}
\hline & \multicolumn{3}{|c|}{ Anaplastic $(n=8)$} & \multicolumn{3}{|c|}{ Non-anaplastic $(n=103)$} \\
\hline & $\begin{array}{l}\text { SRC-1 } \\
(n=7)\end{array}$ & $\begin{array}{l}\text { HER2 } \\
(n=0)\end{array}$ & $\begin{array}{l}\text { NCoR } \\
(n=0)\end{array}$ & $\begin{array}{l}\text { SRC-1 } \\
(n=18)\end{array}$ & $\begin{array}{c}\text { HER2 } \\
(n=18)\end{array}$ & $\begin{array}{c}\text { NCoR } \\
(n=57)\end{array}$ \\
\hline SRC-1 & - & - & - & - & $7 / 18 P<0.001$ & $1 / 57 P<0.001^{*}$ \\
\hline HER2 & $0 / 7$ & - & - & $11 / 18 P<0.001$ & - & $2 / 57 P<0.001^{*}$ \\
\hline NCoR & $0 / 7$ & - & - & $1 / 18 P<0.001^{*}$ & $2 / 18 P<0.001^{*}$ & - \\
\hline Recurrence & $7 / 7$ & - & - & $9 / 18 P=0.001$ & $8 / 18 P<0.005$ & $8 / 57 P=0.214$ \\
\hline Well differentiated & $0 / 7$ & - & - & $1 / 18 P<0.001^{*}$ & $0 / 18 P<0.001^{*}$ & $52 / 57 P<0.001$ \\
\hline
\end{tabular}

*Inverse relationship. 
strong correlation between SRC-1 expression and reduced disease-free survival.

Abnormalities in growth factor signalling pathways play an intrinsic role in endocrine tumour disease progression. In human breast cancer, the growth factor receptor HER2 is overexpressed in 20-30\% of tumours (Berger et al. 1988). Molecular and clinical evidence suggests that crosstalk between steroid receptor and growth factor pathways contributes to endocrine insensitivity, at least in part through phosphorylation and activation of coactivator proteins (Osborne et al. 2005). We have previously described a positive association between expression of the coactivators, SRC-1 and AIB1, and the growth factor receptor, HER2, in a cohort of breast tumour patients (Myers et al. 2005) and shown that the risk ratio of recurrence in HER2-positive patients with elevated SRC-1 is 16.82 (Fleming et al. 2004).

Several groups have reported HER2 expression in thyroid cancer (Ensinger et al. 2003, Mondi et al. 2003, Wiseman et al. 2008), though results from these studies remain inconclusive. Mondi et al. (2003) observed no significant expression of HER2 in benign or malignant thyroid tissue, and Wiseman et al. (2008) found that HER2 was not significantly expressed in anaplastic tumours. However, others have reported that in papillary thyroid carcinoma, expression of HER2 was associated with disease recurrence (Ensinger et al. 2003). In this study, though no detectable levels of HER2 were observed in anaplastic tumours, $17 \%$ of non-anaplastic tumours were positive for HER2. Expression of the tyrosine kinase receptor was associated with capsular invasion, inversely with well-differentiated tumours and positively with disease recurrence. Of interest, in the non-anaplastic tumour population, HER2 was positively associated with SRC-1 and inversely associated with NCoR.

This is the first translational study to take a comprehensive look at oestrogen signalling in relation to the contribution of steroid receptor coregulatory proteins and tyrosine kinase receptor status in human thyroid cancer. Data that have emerged from this study establish ER signalling, in conjunction with its corepressor protein NCoR as a mediator of welldifferentiated tumours with a favourable prognosis. The coactivator protein SRC-1 is associated with invasion, poor differentiation, tumour recurrence and reduced disease-free survival. In non-anaplastic tumours, SRC-1 strongly associates with HER2, suggesting that crosstalk with the tyrosine kinase receptor may activate SRC-1 in this tumour subtype. In anaplastic thyroid cancer, SRC-1 does not appear to mediate these effects through the steroid receptor ER.
The ability of steroid coactivator proteins to function independently of ER has been previously described by our group and others (Goel \& Janknecht 2004, Myers et al. 2005, Al-azawi et al. 2008). Though the signalling mechanism of SRC-1 in cellular dedifferentiation in anaplastic thyroid carcinoma has yet to be resolved, this protein may represent a new therapeutic target for this rare, but rapidly fatal disease.

\section{Declaration of interest}

The authors declare that there is no conflict of interest that could be perceived as prejudicing the impartiality of the research reported.

\section{Funding}

This work was supported by Breast Cancer Ireland (grant number 06/920, 2006).

\section{Author contribution statement}

D Kavanagh, E Myers, M McIlroy and F Bane performed the experiments; M McIlroy was responsible for statistical analysis and manuscript preparation; $\mathrm{T}$ Crotty, pathology expertise; E McDermott and A Hill provided tumour specimens and were instrumental in creating a clinical framework to relate the data back to the patient; Leonie Young designed the experiments and was responsible for the successful execution of the study.

\section{References}

Al-azawi D, Ilroy MM, Kelly G, Redmond AM, Bane FT, Cocchiglia S, Hill AD \& Young LS 2008 Ets-2 and p160 proteins collaborate to regulate c-Myc in endocrine resistant breast cancer. Oncogene 27 3021-3031.

Berger MS, Locher GW, Saurer S, Gullick WJ, Waterfield MD, Groner B \& Hynes NE 1988 Correlation of c-erbB-2 gene amplification and protein expression in human breast carcinoma with nodal status and nuclear grading. Cancer Research 48 1238-1243.

Chen JD \& Evans RM 1995 A transcriptional corepressor that interacts with nuclear hormone receptors. Nature $\mathbf{3 7 7}$ 454-457.

Egawa C, Miyoshi Y, Iwao K, Shiba E \& Noguchi S 2001 Quantitative analysis of estrogen receptor -alpha and -beta messenger RNA expression in normal and malignant thyroid tissues by real-time polymerase chain reaction. Oncology 61 293-298.

Ensinger C, Prommegger R, Kendler D, Gabriel M, Spizzo G, Mikuz G \& Kremser R 2003 Her2/neu expression in poorly-differentiated and anaplastic thyroid carcinomas. Anticancer Research 23 2349-2353.

Figge J 1999 Epidemiology of thyroid cancer. In Thyroid Cancer: a Comprehensive Guide to Clinical Management, pp 77-83. Ed L Wartofsky. Totowa: Humana Press. 
Fleiss JL 1986 Introduction. In The Design and Analysis of Clinical Experiments. Ed. JL Fleiss. New York: John Wiley and Sons.

Fleming FJ, Myers E, Kelly G, Crotty TB, McDermott EW, O'Higgins NJ, Hill AD \& Young LS 2004 Expression of SRC-1, AIB1, and PEA3 in HER2 mediated endocrine resistant breast cancer; a predictive role for SRC-1. Journal of Clinical Pathology 57 1069-1074.

Goel A \& Janknecht R 2004 Concerted activation of ETS protein ER 81 by $\mathrm{p} 160$ coactivators, the acetyltransferase p300 and the receptor tyrosine kinase HER2/Neu. Journal of Biological Chemistry 279 14909-14916.

Goretski PE, Frilling A, Simon D \& Roeher HD 1990 Growth regulation of normal thyroids and thyroid tumours in man. Recent Results in Cancer Research 118 48-63.

Harvey JM, Clarke GM, Osborne CK \& Allred DC 1999 Estrogen receptor status by immunohistochemistry is superior to the ligand binding assay for predicting response to adjuvant endocrine therapy in breast cancer. Journal of Clinical Oncology 17 1474-1482.

Jenster G \& Spencer TE 1997 Steroid receptor induction of gene transcription: a two-step model. PNAS 94 7879-7884.

Kishino T, Watanabe M, Kimura M \& Sugawara I 1997 Anti-proliferative effect of toremifene and tamoxifen on estrogen receptor-lacking anaplastic thyroid carcinoma cell lines. Biological \& Pharmaceutical Bulletin 20 1257-1260.

Lee SH, Kim KM, Jung BH, Chung WY, Cheong SP \& Chung BC 2003 Estrogens in female thyroid cancer: alteration of urinary profiles in pre- and post-operative cases. Cancer Letters 189 27-32.

Manole D, Schildknecht B, Gosnell B, Adams E \& Derwahl M 2001 Estrogen promotes growth of human thyroid tumor cells by different molecular mechanisms. Journal of Clinical Endocrinology and Metabolism 86 1072-1077.

McIlroy M, Fleming FJ, Buggy Y, Hill AD \& Young LS 2006 Tamoxifen-induced ER-alpha-SRC-3 interaction in HER2 positive human breast cancer: a possible mechanism for ER isoform specific recurrence. Endocrine-Related Cancer 13 1135-1145.

Mondi MM, Rich R, Ituarte P, Wong M, Bergman S, Clark OH \& Perrier ND 2003 HER2 expression in thyroid tumors. American Surgeon 69 1100-1103.

Murakawa T, Tsuda H, Tanimoto T, Tanabe T, Kitahara S \& Matsubara O 2005 Expression of KIT, EGFR, HER-2 and tyrosine phosphorylation in undifferentiated thyroid carcinoma: implication for anew therapeutic approach. Pathology International 55 757-765.

Myers E, Fleming FJ, Crotty T, Kelly G, McDermott EW, O’Higgins NJ, Hill AD \& Young LS 2004 Inverse relationship between ER-beta and SRC-1 predicts outcome in endocrine-resistant breast cancer. British Journal of Cancer 91 1687-1693.

Myers E, Hill AD, Kelly G, McDermott EW, O’Higgins NJ, Buggy Y \& Young LS 2005 Associations and interactions between Ets-1 and Ets-2 and coregulatory proteins, SRC-1, AIB1, and NCoR in breast cancer. Clinical Cancer Research 11 2111-2122.

Osborne CK, Bardou V, Hopp TA, Chamness GC, Hilsenbeck SG, Fuqua SA, Wong J, Allred DC, Clark GM \& Schiff R 2003 Role of the estrogen receptor coactivator AIB1 (SRC-3) and HER-2/neu in tamoxifen resistance in breast cancer. Journal of the National Cancer Institute 95 353-361.

Osborne CK, Shou J, Massarweh S \& Schiff R 2005 Crosstalk between estrogen receptor and growth factor receptor pathways as a cause for endocrine therapy resistance in breast cancer. Clinical Cancer Research 11 865s-870s.

Qin L, Liu Z, Chen H \& Xu J 2009 The steroid receptor coactivator-1 regulates twist expression and promotes breast cancer metastasis. Cancer Research 69 3819-3827.

Redmond AM, Bane F, Stafford AT, Crotty TB, McIlroy M, Hill AD \& Young LS 2009 Coassociation of ER and p160 proteins predicts resistance to endocrine treatment; SRC-1 is an independent predictor of breast cancer recurrence. Clinical Cancer Research 15 2098-2106.

Rossing MA, Voigt LF, Wicklund KG \& Daling JR 2000 Reproductive factors and risk of papillary thyroid cancer in women. American Journal of Epidemiology 151 765-772.

Sherman S 2003 Thyroid carcinoma. Lancet 361 501-512.

Smith CL \& O'Malley BW 2004 Coregulator function: a key to understanding tissue specificity of selective receptor modulators. Endocrine Reviews 25 45-71.

Teppo L, Hakulinen T \& Eurocare Working Group 1998 Variation in survival of adults with thyroid cancer in Europe. European Journal of Cancer 34 2248-2252.

Vivacqua A, Bonofiglio D, Albanito L, Madeo A, Rago V, Carpino A, Musti AM, Picard D, Ando S \& Maggiolini M 2006 17Beta-estradiol, genistein and 4-hydroxytamoxifen induce the proliferation of thyroid cancer cells through the G protein-coupled receptor GPCR30. Molecular Pharmacology 70 1414-1423.

Wang S, Yuan Y, Liao L, Kuang SQ, Tien JC, O’Malley BW \& Xu J 2009 Disruption of the SRC-1 gene in mice suppresses breast cancer metastasis. PNAS 106 151-156.

Wiseman SM, Griffith OL, Melck A, Masoudi H, Gown A, Nabi IR \& Jones SJ 2008 Evaluation of type 1 growth factor receptor family expression in benign and malignant thyroid lesions. American Journal of Surgery 195 667-673.

Xu J \& Li Q 2003 Review of the in vivo functions of the p160 steroid receptor coactivator family. Molecular Endocrinology 17 1681-1692.

Zeng Q, Chen GG, Vlantis AC, Tse GM \& van Hasselt CA 2008 The contributions of oestrogen receptor isoforms to the development of papillary and anaplastic thyroid carcinomas. Journal of Pathology 214 425-433. 